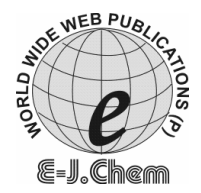

http://www.e-journals.net
ISSN: 0973-4945; CODEN ECJHAO

E-Journal of Chemistry

2009, 6(1), 23-33

\title{
FTIR and Thermal Studies on Nylon-66 and $30 \%$ Glass Fibre Reinforced Nylon-66
}

\author{
JULIE CHARLES*, G. R. RAMKUMAAR, \\ S. AZHAGIRI and S. GUNASEKARAN \\ *Dept. of Physics, S.S.N. College of Engineering, \\ Old Mahabalipuram Road, Kalavakkam 603 110, India. \\ Spectrophysics Research Laboratory, \\ PG and Research Dept. of Physics, \\ Pachaiyappa's College, Chennai 600 030, India. \\ juliecharles2005@gmail.com
}

Received 24 May 2008; Accepted 20 July 2008

\begin{abstract}
The present study deals with the characterization of the polymeric materials viz., nylon-66 and 30\% glass fibre reinforced nylon-66 (GF Nylon-66) by employing FTIR and thermal measurements. The complete vibrational band assignment made available for nylon-66 and GF nylon-66 using FTIR spectra confirm their chemical structure. FTIR spectroscopy provides detailed information on polymer structure through the characteristic vibrational energies of the various groups present in the molecule. The thermal behavior of nylon-66 and GF nylon-66 essential for proper processing and fabrication was studied from TGA and DTA thermograms. The thermal stability of the polymers was studied from TGA and the activation energy for the degradation of the polymeric materials was calculated using Murray-White plot and Coats-Redfern plot. The polymer with high activation energy is more thermally stable. GF nylon-66 is found to be more thermally stable than nylon-66. The major thermal transitions such as crystalline melting temperature $\left(\mathrm{T}_{\mathrm{m}}\right)$ and degradation temperature $\left(\mathrm{T}_{\mathrm{d}}\right)$ of the polymers were detected from DTA curves. The melting behaviour of the polymer depends upon the specimen history and in particular upon the temperature of crystallization. The melting behaviour also depends upon the rate at which the specimen is heated. The various factors such as molar mass and degree of chain branching govern the value of $\mathrm{T}_{\mathrm{m}}$ in different polymers.
\end{abstract}

Keywords: Nylon-66, GF Nylon-66, FTIR spectra, Thermal stability, Activation energy, Thermal transitions and Molecular symmetry. 


\section{Introduction}

Polymer characterization is an essential step in working with polymers. As a rule such efforts are directed towards a specific purpose. The structure and organization of the macromolecules ultimately determine the mechanical, physical and chemical properties of polymers ${ }^{1,2}$. Thus the precise characterization of molecular order is a primary prerequisite to understanding the macroscopic properties of polymeric materials ${ }^{3,4}$. The polymeric materials such as nylon-66 and GF nylon-66 are studied here by utilizing important experimental techniques. The chemical structure of the repeat unit of nylon-66 is presented in Figure 1. The polyamides were the first engineering thermoplastics produced specifically by design as a plastic and are the largest family in both production volume and number of applications. Nylon-66 is synthesized by condensation polymerization of hexamethylenediamine and adipic acid. It is crystalline, and the crystals melt at a high temperature. This makes it a good candidate for applications where properties such as high strength, excellent chemical and abrasion resistance, and toughness are sought. In spite of its superior properties, nylon-66 is very sensitive to moisture absorption ${ }^{5}$. Indeed, moisture content must be controlled during melt processing of nylon-66.

There is however always a need to improve properties of nylon-66 to meet some specific applications such as under-the-hood applications where humidity, high temperature and repeated impact are encountered. One way to alter properties of thermoplastics is to reinforce them with glass fibers ${ }^{6,7}$. There are several innate characteristics of glass-fibers that make them ideal reinforcements. They have high tensile strength to weight ratio and are perfect elastic materials (typical glass fibers have a maximum elongation of 5\% at break). They are incombustible (typical glass fibers retain approximately $50 \%$ of their strength at $700^{\circ} \mathrm{F}$ ) and have a low thermal expansion coefficient. They do not absorb moisture and are dimensionally stable.

Adding up to $40 \%$ by weight of glass fibers to nylon- 66 increases strength and rigidity and decreases the coefficient of thermal expansion. The most significant effect is the retention of impact strength down to very low temperatures. In virtually all thermoplastics, impact strengths at low temperatures improve with increasing glass fiber content. The heat distortion temperature is improved most markedly in nylon, but less so in most other thermoplastics.

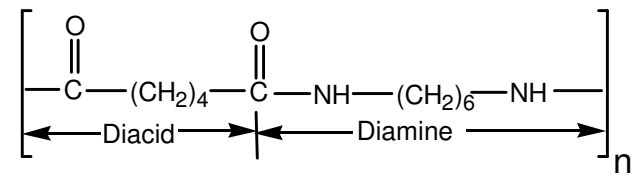

Figure 1. Repeat unit of nylon-66

\section{Experimental}

The pure samples of nylon-66 and GF nylon-66 were obtained from Central Institute of Plastic Engineering and Technology (CIPET), Chennai, India. The FTIR spectra have been recorded in the range 4000-400 $\mathrm{cm}^{-1}$ using Bruker IFS $66 \mathrm{~V}$ spectrophotometer at Indian Institute of Technology (I.I.T), SAIF, Chennai, India. The standard sample preparation technique involves making $\mathrm{KBr}$ discs, with finely ground polymer samples dispersed in the discs at concentrations of less than $1 \%$; they are prepared by compressing in a pellet-making press. The $\mathrm{KBr}$ discs with the polymer sample were placed in the IR cell and the spectrum was recorded. IR is a useful and highly specific tool ${ }^{8}$ to identify the chemical nature of the polymer and to determine its composition. For quantitative analysis of microstructure, stereo regularity, branching or crosslinking, in many cases, IR analysis is the simplest and most sensitive method. 
Thermoanalytical techniques are used for characterization of glass transition and melting temperatures, thermal stability and other properties as a function of temperature of polymers and fibres ${ }^{9}$. Thermogravimetric analysis was carried out in a high resolution thermobalance (NETZSCH STA 409 C/CD instrument) at Indian Institute of Technology (I.I.T), Chennai, India. TGA is a technique whereby the weight of a substance in an environment is recorded when the sample is heated or cooled at a controlled rate and change of weight is measured as a function of temperature or time. Approximately 5-6 mg of sample was heated from room temperature to $1400^{\circ} \mathrm{C}$ at a heating rate of $20^{\circ} \mathrm{C} / \mathrm{min}$ with a continuous $\mathrm{N}_{2}$ flow. The sample weight and its rate of weight loss were continuously measured as a function of temperature. The thermal stability of the selected polymeric materials was studied from TGA curves.

DTA involves heating or cooling a test sample and an inert reference under identical conditions, while recording any temperature difference between the sample and reference. This differential temperature is then plotted against time, or against temperature. DTA curves are recorded simultaneously with TGA curves. In the DTA trace, the baseline remains unchanged so long as there is no thermal transition in the sample. First-order transitions, namely crystallization $\left(\mathrm{T}_{\mathrm{c}}\right)$ and melting $\left(\mathrm{T}_{\mathrm{m}}\right)$, appear as peaks in the exothermic and endothermic directions, respectively. After melting the material may undergo decomposition reactions at higher temperatures $\left(\mathrm{T}_{\mathrm{d}}\right)$ which give broad peaks; these may be generally exothermic but are sometimes more complex in shape ${ }^{10}$. The major transition temperatures $T_{m}$ and $T_{d}$ were detected from the DTA thermograms of nylon-66 and GF nylon-66.

\section{Results and Discussion}

Infrared spectroscopy is one of the most often used spectroscopic tools for the study of polymers. Using FTIR spectroscopy, a lot of research work has been done in the recent past for the study of polymers in various ways, e.g. identification of polymers and additives, studies of coupling effects, conformational studies, stereochemical studies, studies relating to crystalline forms, crystallinity of polymers and fibres, orientation in polymers and fibres and end group analysis ${ }^{11,12}$. Polymeric blends of PVC and PET have been irradiated with 3 $\mathrm{MeV}$ proton beam and the radiation induced changes were investigated by N.L. Singh et $a l^{13}$ using FTIR spectroscopy. According to L.Z. Pillon et $a l^{14}$, FTIR has proven to be an excellent technique to detect the presence of hydrogen bonding in the PET/nylon-66 blend. Blends of PET and HDPE with and without a compatibilizing agent were studied by Carlos Guerrero et al using infrared spectroscopy ${ }^{15}$.

IR spectroscopy has been usefully applied for identification of the basic structural units present in the chemical configuration of nylon-66 and GF nylon-66. The FTIR spectra of the polymeric materials are presented in Figures 2 and 3. The complete vibrational band assignment is made available for the selected polymeric materials, thereby confirming their molecular structure ${ }^{16}$. The vibrational frequencies of all the fundamental bands along with their relative intensities and probable assignments are given in Tables 1 and 2. The primary motivation for determining the molecular structure of a polymer using FTIR spectroscopy is to relate the structures to the performance properties of the polymer in end use. If the polymer chains are completely characterized and the structural basis of its properties are known, the polymerization reaction can be optimized and controlled to produce the optimum properties from the particular chemical system. 


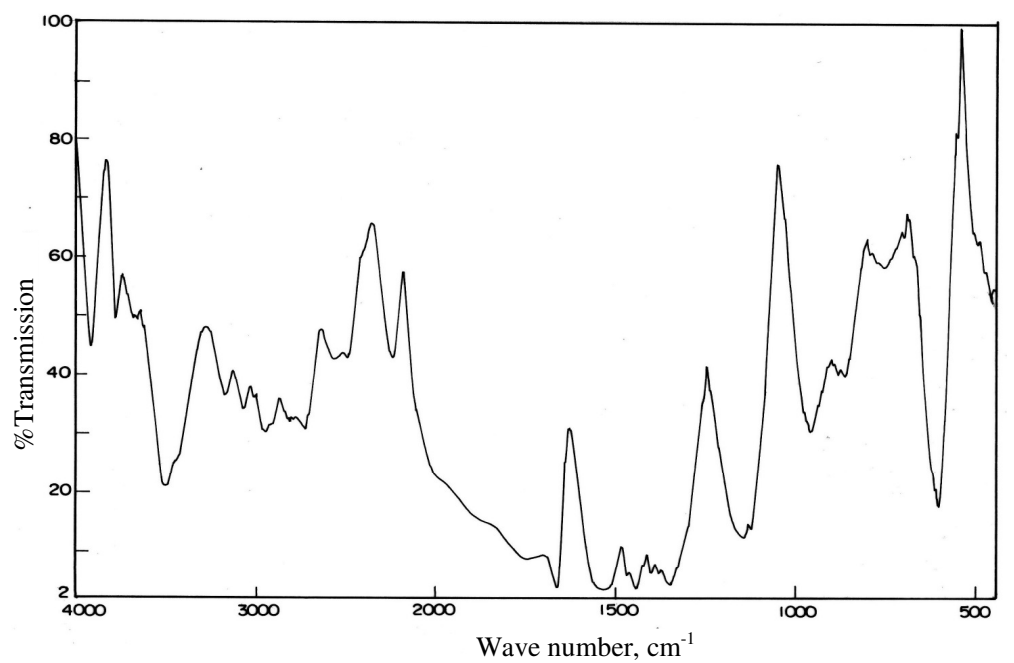

Figure 2. FTIR spectrum of nylon-66

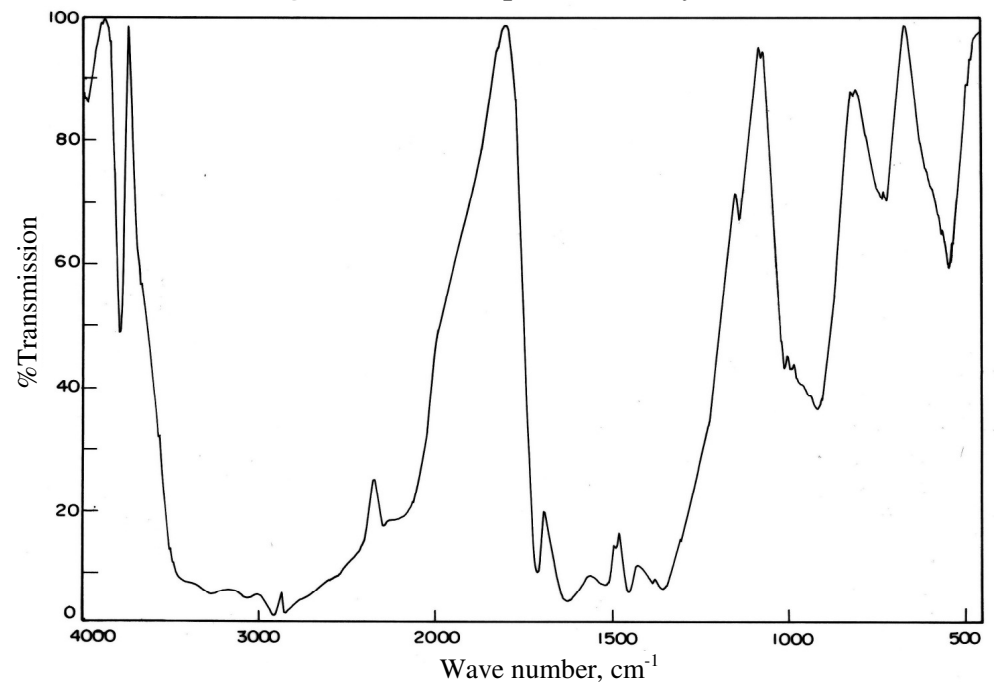

Figure 3. FTIR spectrum of GF nylon-66

One of the important properties of polymeric materials is its thermal behavior. TGA is a thermo analytical method used to study the thermal properties of elastomers. In this procedure, the weight of a sample is continuously monitored as the sample temperature increases. When a sample decomposes or degrades, normally the decomposition components volatilize off, resulting in a change in weight. The continuous weight loss curves for the thermal degradation of unfilled and glass fibre filled nylon are presented in Figures 4 and 5. The thermal stability of the chosen rubber samples was studied from TGA. These thermograms suggest that the samples are thermally stable up to $391^{\circ} \mathrm{C}$. Thermal stability refers to the ability to maintain required mechanical properties such as strength, toughness and elasticity at a given temperature. It is also used to determine the kinetic parameters of degradation of rubber materials. The thermal stability of the selected rubber materials at different temperatures are presented in Table 3. 
Table 1. FTIR spectra and assignment of nylon-66

\begin{tabular}{ccl}
\cline { 1 - 2 } \multicolumn{2}{c}{ Frequency, $\mathrm{cm}^{-1}$} & \multicolumn{1}{c}{ Assignment } \\
\cline { 1 - 2 } FTIR & Intensity & \\
\cline { 1 - 2 } 3182 & $\mathrm{~m}$ & $\mathrm{~N}-\mathrm{H}$ stretching \\
3080 & $\mathrm{~ms}$ & $\mathrm{C}-\mathrm{H}$ asymmetric stretching \\
3020 & $\mathrm{~m}$ & $\mathrm{C}-\mathrm{H}$ symmetric stretching \\
2958 & $\mathrm{~ms}$ & $\mathrm{CH}_{2}$ asymmetric stretching \\
2841 & $\mathrm{~ms}$ & $\mathrm{CH}_{2}$ symmetric stretching \\
1745 & $\mathrm{vs}$ & $\mathrm{C}=\mathrm{O}$ stretching \\
1660 & $\mathrm{vs}$ & Amide I band \\
1541 & $\mathrm{vs}$ & Amide II band/ $\mathrm{CH}_{2}$ asymmetric deformation \\
1447 & $\mathrm{vs}$ & $\mathrm{N}-\mathrm{H}$ deformation/ $\mathrm{CH}_{2}$ scissoring \\
1354 & $\mathrm{vs}$ & Amide III band/ $\mathrm{CH}_{2}$ wagging \\
1149 & $\mathrm{vs}$ & $\mathrm{CCH}$ symmetric bending/CH $\mathrm{C}_{2}$ twisting \\
1128 & $\mathrm{vs}$ & $\mathrm{CCH}$ symmetric bending \\
959 & $\mathrm{~ms}$ & $\mathrm{C}-\mathrm{C}$ stretching \\
755 & $\mathrm{w}$ & $\mathrm{N}-\mathrm{H}$ wagging/ $\mathrm{CH}_{2}$ rocking \\
606 & $\mathrm{~s}$ & $\mathrm{C}-\mathrm{C}$ bending \\
549 & $\mathrm{vw}$ & O=C-N bending \\
\hline
\end{tabular}

vs-very strong s-strong ms-medium strong m-medium w-weak

Table 2. FTIR spectra and assignment of glass filled nylon-66

\begin{tabular}{|c|c|c|}
\hline \multicolumn{2}{|c|}{ Frequency, $\mathrm{cm}^{-1}$} & \multirow{2}{*}{ Assignment } \\
\hline FTIR & Intensity & \\
\hline 3260 & vs & N-H stretching \\
\hline 3070 & vs & $\mathrm{C}-\mathrm{H}$ asymmetric stretching \\
\hline 2920 & vs & $\mathrm{CH}_{2}$ asymmetric stretching \\
\hline 2856 & vs & $\mathrm{CH}_{2}$ symmetric stretching \\
\hline 1716 & vs & $\mathrm{C}=\mathrm{O}$ stretching \\
\hline 1630 & vs & Amide I band \\
\hline 1522 & vs & Amide II band/ $\mathrm{CH}_{2}$ asymmetric deformation \\
\hline 1456 & vs & $\mathrm{N}-\mathrm{H}$ deformation $/ \mathrm{CH}_{2}$ scissoring \\
\hline 1355 & vs & Amide III band/ $\mathrm{CH}_{2}$ wagging \\
\hline 1142 & $\mathrm{w}$ & $\mathrm{CCH}$ symmetric bending/ $\mathrm{CH}_{2}$ twisting \\
\hline 1014 & $\mathrm{~m}$ & C-C stretching \\
\hline 820 & vVw & $\mathrm{N}-\mathrm{H}$ wagging \\
\hline 723 & vw & $\mathrm{CH}_{2}$ rocking \\
\hline 568 & $\mathrm{w}$ & $\mathrm{C}-\mathrm{C}$ deformation \\
\hline 547 & $\mathrm{w}$ & $\mathrm{O}=\mathrm{C}-\mathrm{N}$ bending \\
\hline
\end{tabular}

vs-very strong s-strong ms-medium strong m-medium w-weak

Table 3. Thermal stability of polymeric materials

\begin{tabular}{lccccccccc}
\hline \multirow{2}{*}{ Sample } & \multicolumn{7}{c}{ Temperature, ${ }^{\circ} \mathrm{C}$ corresponding to weight loss } \\
\cline { 2 - 10 } & $10 \%$ & $20 \%$ & $30 \%$ & $40 \%$ & $50 \%$ & $60 \%$ & $70 \%$ & $80 \%$ & $90 \%$ \\
\hline Nylon-66 & 392 & 419 & 431 & 441 & 448 & 454 & 495 & - & - \\
GF Nylon-66 & 403 & 422 & 434 & 443 & 453 & 460 & - & - & - \\
\hline
\end{tabular}




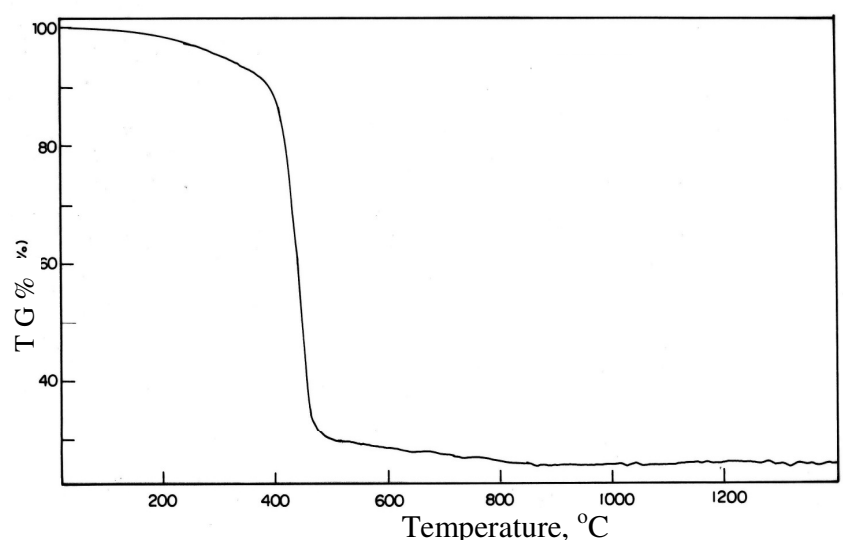

Figure 4. TGA thermogram of nylon-66

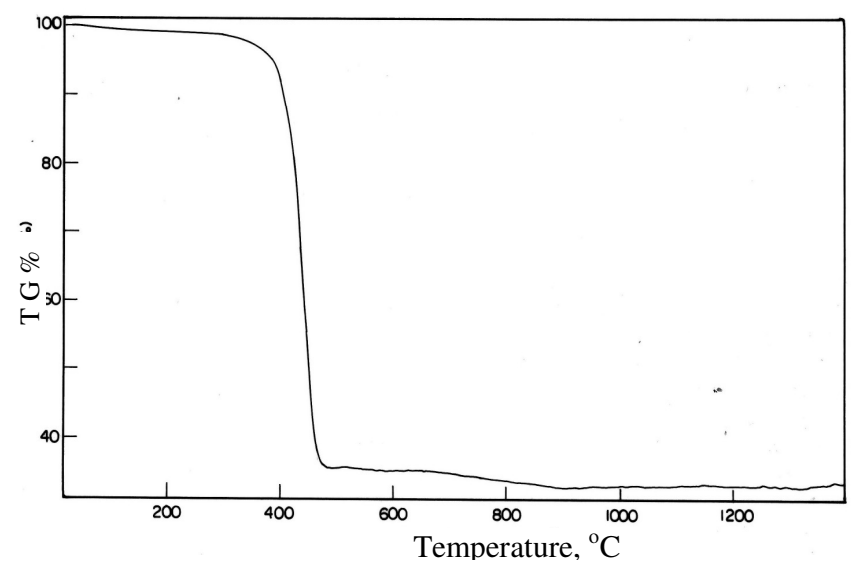

Figure 5. TGA thermogram of GF nylon-66

The degradation process is single stage for nylon- $66^{17}$ and $30 \%$ glass fibre reinforced nylon66 . Both the polymers have undergone $63 \%$ decomposition in this stage. Between $366^{\circ} \mathrm{C}$ and $495^{\circ} \mathrm{C}, 63 \%$ of nylon-66 was degraded. $63 \%$ of glass filled nylon-66 was degraded between $340^{\circ} \mathrm{C}$ and $502^{\circ} \mathrm{C}$. The degradation temperatures corresponding to $30 \%$ and $60 \%$ weight losses are $431^{\circ} \mathrm{C}$ and $454^{\circ} \mathrm{C}$ for nylon-66. The TGA curve of glass filled nylon-66 shows a weight loss of $30 \%$ at $434^{\circ} \mathrm{C}$ and $60 \%$ at $460^{\circ} \mathrm{C}$. Unfilled nylon degrades at slightly lower temperatures than glass filled nylon. Further nylon-66 undergoes $70 \%$ degradation at $495^{\circ} \mathrm{C}$. This means that glass filled nylon is thermally more stable than unfilled nylon. On the whole $75 \%$ of nylon- 66 gets degraded and $67 \%$ of glass filled nylon- 66 gets degraded at $1400^{\circ} \mathrm{C}$ which further confirms that glass filled nylon-66 is thermally more stable than unfilled nylon-66.

\section{Activation energies of degradation of polymeric materials}

Activation energy is the minimum amount of energy that is required to activate atoms or molecules to a condition in which they can undergo chemical transformation or physical transport. Activation energy calculations for the degradation of nylon-66 and GF nylon-66 were made from TGA curves using Murray-White plot $^{18}$ and Coats-Redfern plot $^{19}$. A linear 
correlation was obtained by plotting the logarithm of heating rate against the reciprocal of the absolute temperature. In Murray-White method, a linear correlation was obtained by plotting $\mathrm{T}^{-1} \times 10^{-3}\left(\mathrm{~K}^{-1}\right)$ against $[\ln (\ln (1-\mathrm{C})-2 \ln \mathrm{T}]$. In Coats-Redfern method, a linear correlation was obtained by plotting $\mathrm{T}^{-1} \times 10^{-3}\left(\mathrm{~K}^{-1}\right)$ against $\log [\ln (1-\mathrm{C})] / \mathrm{T}^{2}$. The method of calculating activation energy ${ }^{20,21}$ for the degradation of nylon-66 and GF nylon-66 are given in Tables 4 and 5. The Arrhenius plot for degradation of polymers using Murray-White plot and Coats-Redfern plot is presented in Figure 6. Activation energy calculated from TGA curve using the two methods is presented in Table 6.

Murray and White Method

$\mathrm{T}^{-1} \times 10^{-3}\left(\mathrm{~K}^{-1}\right) V s \ln [\ln (1-\mathrm{C})]-2 \ln \mathrm{T}$
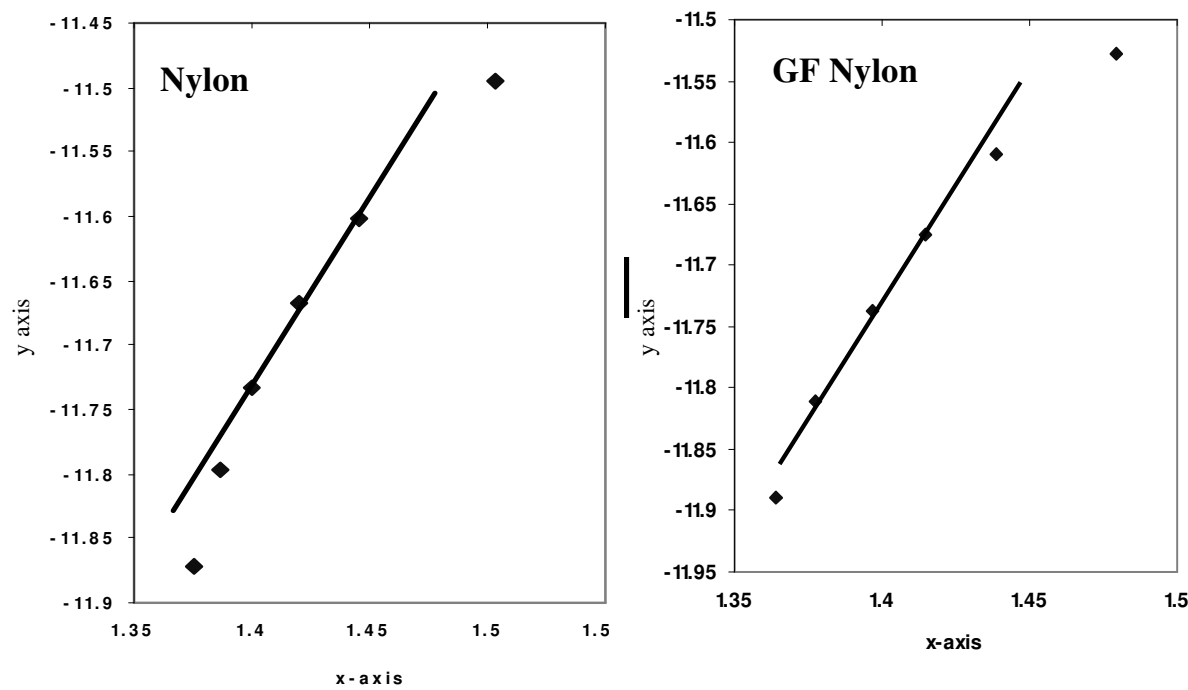

Coats and Redfern Method

$\mathrm{T}^{-1} \times 10^{-3}\left(\mathrm{~K}^{-1}\right) V s \log [\ln (1-\mathrm{C})] / \mathrm{T}^{2}$
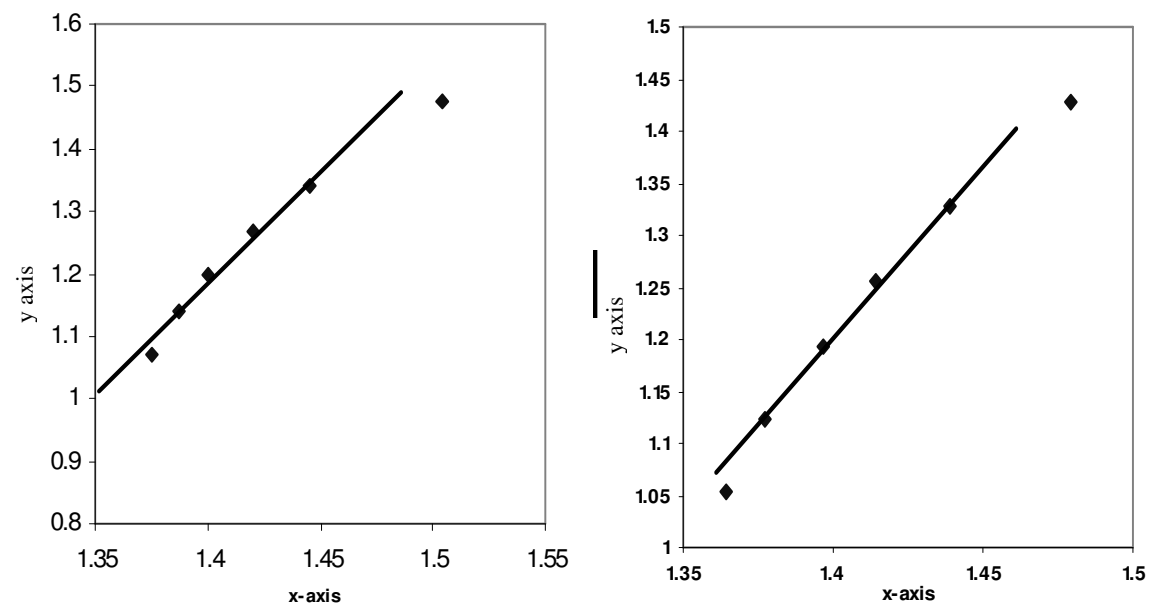

Figure 6. Arrhenius plot of degradation of polymer materials 
Table 4. Calculation of activation energy for the degradation of nylon-66

\begin{tabular}{cccccccc}
\hline \multirow{2}{*}{ Degradation\% } & $\begin{array}{c}\mathrm{T} \\
\mathrm{K}\end{array}$ & $\begin{array}{c}\mathrm{T}^{-1} \times 10^{-3} \\
\mathrm{~K}^{-1}\end{array}$ & $1-\mathrm{C}$ & $2 \ln \mathrm{T}$ & $\mathrm{T}^{2}$ & $\begin{array}{c}\ln [\ln (1-\mathrm{C})] \\
-2 \ln \mathrm{T}\end{array}$ & $\begin{array}{c}\log [\ln (1-\mathrm{C})] \\
/ \mathrm{T}^{2} \times 10^{6}\end{array}$ \\
\hline 10 & 665 & 1.5037 & 90 & 12.9995 & 442225 & -11.4955 & 1.476 \\
20 & 692 & 1.4450 & 80 & 13.0791 & 478864 & -11.6016 & 1.339 \\
30 & 704 & 1.4204 & 70 & 13.1135 & 495616 & -11.667 & 1.267 \\
40 & 714 & 1.4005 & 60 & 13.1417 & 509796 & -11.7322 & 1.2 \\
50 & 721 & 1.3869 & 50 & 13.1612 & 519841 & -11.7972 & 1.139 \\
60 & 727 & 1.3755 & 40 & 13.1778 & 528529 & -11.8725 & 1.072 \\
\hline
\end{tabular}

Table 5. Calculation of activation energy for the degradation of 30\% GF nylon-66

\begin{tabular}{cccccccc}
\hline$\%$ & $\mathrm{~T}$ & $\mathrm{~T}^{-1} \times 10^{-3}$ & & & & & \\
Degradation & $\mathrm{K}$ & $\mathrm{K}^{-1}$ & $1-\mathrm{C}$ & $2 \ln \mathrm{T}$ & $\mathrm{T}^{2}$ & $\begin{array}{c}\ln [\ln (1-\mathrm{C})]- \\
2 \ln \mathrm{T}\end{array}$ & $\begin{array}{c}\log [\ln (1-\mathrm{C})] \\
/ \mathrm{T}^{2} \times 10^{6}\end{array}$ \\
\hline 10 & 676 & 1.4792 & 90 & 13.0323 & 456976 & -11.5283 & 1.429 \\
20 & 695 & 1.4388 & 80 & 13.0878 & 483025 & -11.6103 & 1.328 \\
30 & 707 & 1.4144 & 70 & 13.1220 & 499849 & -11.6755 & 1.256 \\
40 & 716 & 1.3966 & 60 & 13.1473 & 512656 & -11.7378 & 1.193 \\
50 & 726 & 1.3774 & 50 & 13.1751 & 527076 & -11.8111 & 1.123 \\
60 & 733 & 1.3642 & 40 & 13.1942 & 537289 & -11.8889 & 1.054 \\
\hline
\end{tabular}

Table 6. Activation energy for the degradation of polymer materials

\begin{tabular}{lcc}
\hline \multirow{2}{*}{ Sample } & \multicolumn{2}{c}{ Activation energy $\mathrm{E}_{\mathrm{a}}$ in kJ/mol } \\
\cline { 2 - 3 } & Murray-White Method & Coats-Redfern Method \\
\hline Nylon-66 & 0.1427 & 0.2169 \\
GF Nylon-66 & 0.4189 & 0.5021 \\
\hline
\end{tabular}

It is evident from Table 6, Glass filled Nylon-66 has high decomposition activation energy than unfilled nylon- $66^{17}$. TGA curves show that glass filled nylon degrades at slightly higher temperatures than unfilled nylon. Moreover, $25 \%$ of unfilled nylon remains undecomposed whereas $33 \%$ of glass filled nylon remains as a residue material. Thus, the polymeric materials with high activation energy are more thermally stable which is supported by ${ }^{22,23}$.

The DTA curves for the polymers are shown in Figures 7 and 8. The major transition temperatures such as crystalline melting temperature $\left(T_{m}\right)$ and degradation temperature $\left(T_{d}\right)$ were identified from DTA curves of polymers. There are several characteristics of the melting behaviour of polymers which distinguishes them from other materials. It is not possible to define a single melting temperature for a polymer sample as the melting generally takes place over a range of temperature. The melting behaviour depends upon the specimen history and in particular upon the temperature of crystallization and the rate at which the specimen is heated ${ }^{24}$. There is found to be a strong dependence of the observed melting temperature of a polymer crystal, $T_{m}$, upon the crystal thickness 1 . A process which affects the melting behaviour of crystalline polymers and is of interest in its own right is annealing. It is found that when crystalline polymers are heated to temperatures just below the melting temperature, there is an increase in lamellar crystal thickness. The driving force is the reduction in free energy gained by lowering the surface area of a lamellar crystal when it becomes thicker and less wide. The lamellar thickening only happens at relatively high temperatures when there is sufficient thermal energy available to allow the necessary molecular motion to take place. A certain amount of annealing usually takes place when a 
crystalline polymer sample is heated and melted. The increase in lamellar thickness, 1 , causes an increase in $T_{m}$. This means that the measured melting temperature will depend upon the heating rate because annealing effects will be lower for more rapid rates of heating.

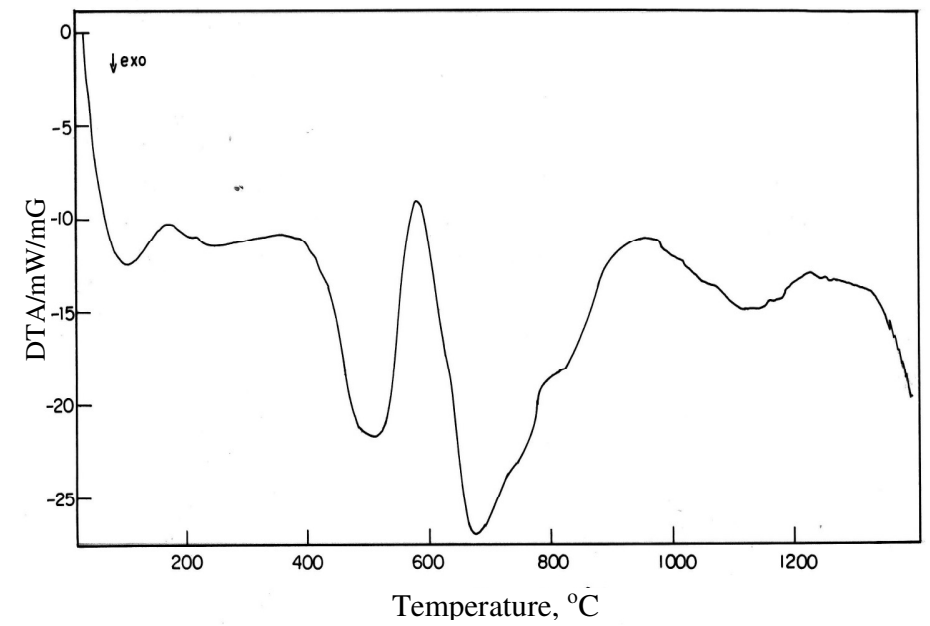

Figure 7. DTA thermogram of nylon-66

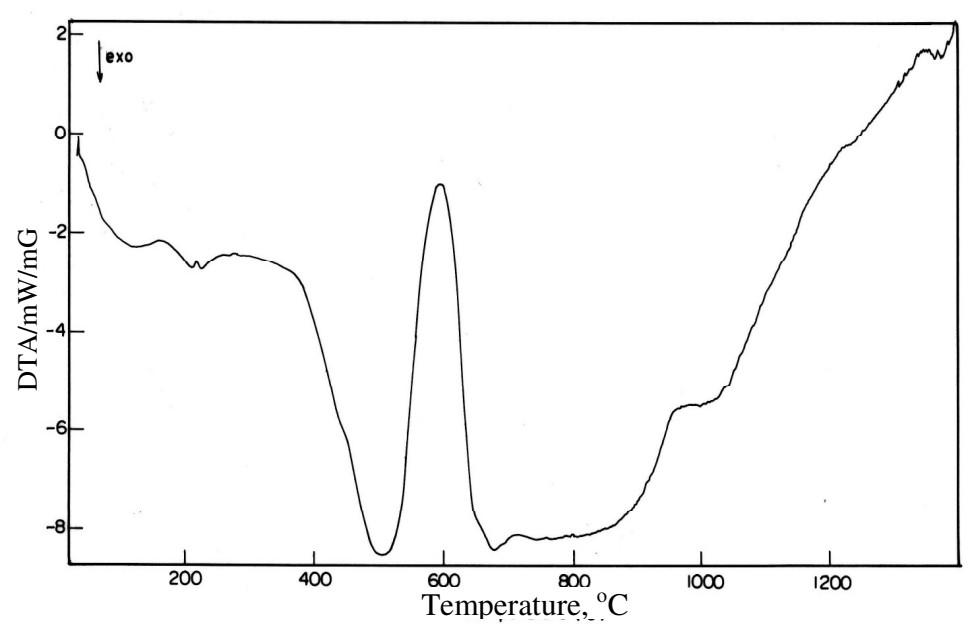

Figure 8. DTA thermogram of GF nylon-66

The important thermal transitions such as $T_{m}$ and $T_{d}$ detected from DTA curves are presented in Table 7. The use of polymers in many practical applications is often limited by their relatively low melting temperatures. Because of this there has been considerable interest in determining the factors which control the value of $\mathrm{T}_{\mathrm{m}}$ and in synthesizing polymers which have high melting temperatures ${ }^{25}$. For a particular type of polymer the value of $\mathrm{T}_{\mathrm{m}}$ depends upon the molar mass and degree of chain branching. Chain ends and branches can be thought of as impurities which depress the melting points of polymer crystals. In 1882, Thomas Carnelley observed that high molecular symmetry is associated with high melting point ${ }^{26}$. Symmetrical molecules in crystalline form have higher melting temperatures and exhibit lower solubility compared with molecules of similar structure but with lower symmetry. Symmetry 
in a molecule imparts a positive amount of residual entropy in the solid phase. This means that the entropy of a substance of symmetric molecules is greater than the entropy of substance of a similar, but non-symmetric molecule. Hence, it is concluded from Table 7 that GF Nylon with high crystalline melting point has high molecular symmetry, low solubility and high entropy.

Table 7. Thermal transition of polymers

\section{Conclusion}

\begin{tabular}{lcc}
\hline \multicolumn{1}{c}{ Sample } & \multicolumn{2}{c}{ Peak Temperature, ${ }^{\circ} \mathrm{C}$} \\
& $\mathrm{T}_{\mathrm{m}}$ & $\mathrm{T}_{\mathrm{d}}$ \\
Nylon-66 & 171.3 & 366495 \\
GF Nylon-66 & 215.6 & 395502 \\
\hline
\end{tabular}

The characterization studies on nylon and glass fibre reinforced nylon have been carried out using important experimental techniques. Their molecular structure was confirmed using FTIR spectroscopic technique. Once the molecular structure of a polymer is understood using FTIR spectroscopy, it becomes easy for a polymer scientist to relate the polymer structure to its performance properties in end use. The thermal stability of the polymeric materials was studied using TGA thermograms. The thermal study shows that glass fibre reinforced nylon is more thermally stable than unfilled nylon. The activation energy was calculated in $\mathrm{KJ} / \mathrm{mol}$ for the degradation of polymers using Murray-White method and Coats-Redfern method. GF Nylon is found to have high activation energy calculated using both the methods. Since high decomposition activation energy is associated with high thermal stability, GF Nylon is considered to be more thermally stable than unfilled nylon. Finally, the major transition temperatures $T_{m}$ and $T_{d}$ were identified from DTA curves. The higher $T_{m}$ value indicates the crystalline nature of the polymer. This means that at room temperature, GF Nylon has a high degree of crystallinity than unfilled nylon. Thus it is concluded that the elastomers with high melting point have high molecular symmetry, low solubility and high entropy.

\section{References}

1. Haslam $\mathrm{J}$ and Willis $\mathrm{H}$ A, Identification and Analysis of Plastics, $2^{\text {nd }}$ Ed., Van Nostrand, New Jersey, 1972.

2. Sandler S, Karo W, Bonesteel J and Pearce E M, Polymer Synthesis and Characterization: A Laboratory manual, Academic Press, Finland, 1998.

3. Carraher C, Polymer Chemistry, $6^{\text {th }}$ Ed., Dekker, New York, 2003.

4. Bicerano J, Prediction of Polymer Properties, Dekker, New York, 2002.

5. Melvin I Kohan, Nylon Plastics, John Wiley \& Sons, USA, 1973.

6. John Murphy, The Reinforced Plastics Handbook, Elsevier, UK, 1998.

7. Donald V Rosato and Dominick V Rosato, Reinforced Plastics Hand Book, $3^{\text {rd }}$ Ed., Elsevier, UK, 2004.

8. Jack L Koenig, Spectroscopy of Polymers, $2^{\text {nd }}$ Ed., Elsevier Science Inc., New York, 1999.

9. Donald C Hylton, Understanding Plastics Testing, Carl Hanser Verlag, Munich, 2004.

10. Spells S J, Characterization of Solid Polymers-New Techniques and developments, Chapman \& Hall, UK, 1994.

11. Gupta V B and Kothari V K, Manufactured Fibre Technology (Eds), Springer, New Delhi, 1997.

12. Henniker J C, Infrared Spectrometry of Industrial Polymers, Academic Press, New York, 1967. 
13. Singh N L, Nilam Shah, Singh K P and Desai C F, Proceedings of the $22^{\text {nd }}$ International Conference on Nuclear Tracks in Solids, Issues 2 - 6, 2005, 40, 741,

14. Pillon L Z, Utracki L A and Pillon D W, Polymer Engineering and Science, 27, 562.

15. Carlos Guerrero, Toma's Lozano, Virgilio Gonza'lez and Eliud Arroyo, J Appl Polymer Sci., 2001, 82, 1382.

16. Nakamoto K, Infrared and Raman spectra of Inorganic and Coordination compounds, $5^{\text {th }}$ Ed., J Wiley \& Sons, New York, 1997.

17. Singh R P, Shrojal M Desai and Pathak G, J Appl. Polymer Sci., 2003, 87, 2146.

18. Murray P and White J, Trans. Br. Ceram. Soc., 1955, 54, 151.

19. Coats A W and Red Fern J P, Nature, 1964, 201, 68.

20. Mittemeijer E J, J Mater Sci., 1992, 27, 3977.

21. Ortega A, Int J Chem Kinet., 2002, 34, 193.

22. De-Yi Wang, Yu-Zhong Wang, Jun-Sheng Wang, Dan-Qi Chen, Qian Zhou, Bing Yang and Wei-Yi Li, Polym Degrad Stabil., 2005, 87,171.

23. Chin-Lung Chiang, Ri-Cheng Chang and Yie-Chan Chiu, Thermochimica Acta, 2007, 453, 97.

24. Young R J and Lovell P A, Introduction to Polymers, $2^{\text {nd }}$ Ed., Nelson Thornes Ltd, UK, 1991.

25. Andreas Seeger, Detlef Freitag, Frank Freidel and Gerhard Luft, Thermochimica Acta, 2004, 424, 175.

26. Brown R J C and Brown R F C, J Chem Edu., 2000, 77, 724. 


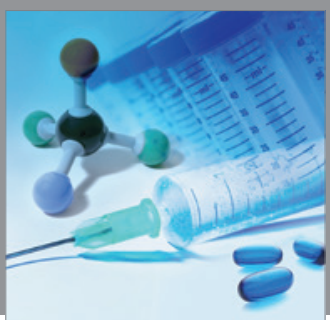

International Journal of

Medicinal Chemistry

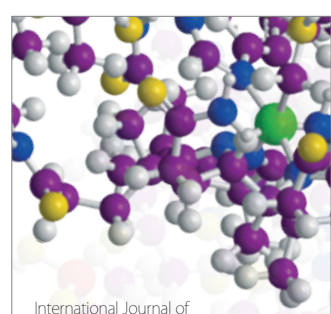

Carbohydrate Chemistry

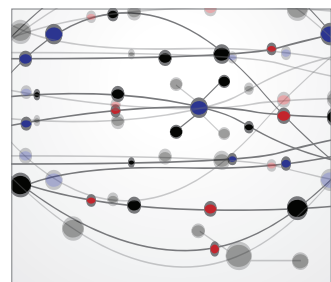

The Scientific World Journal
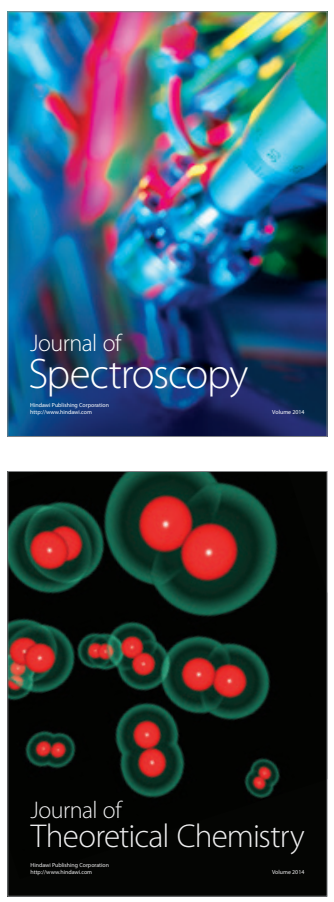
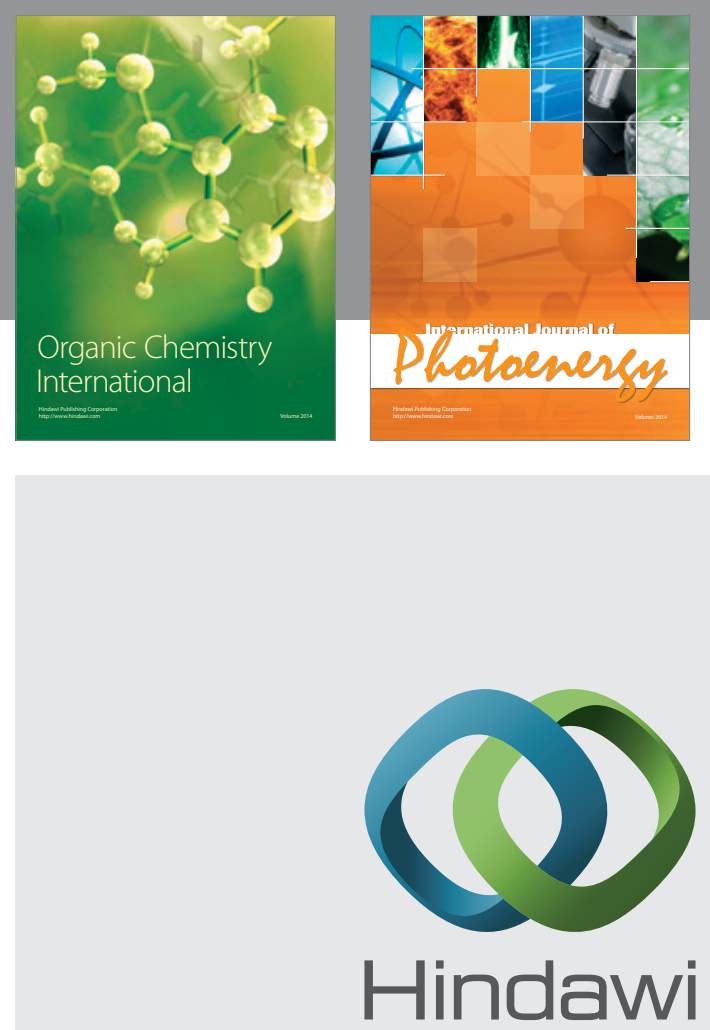

Submit your manuscripts at

http://www.hindawi.com
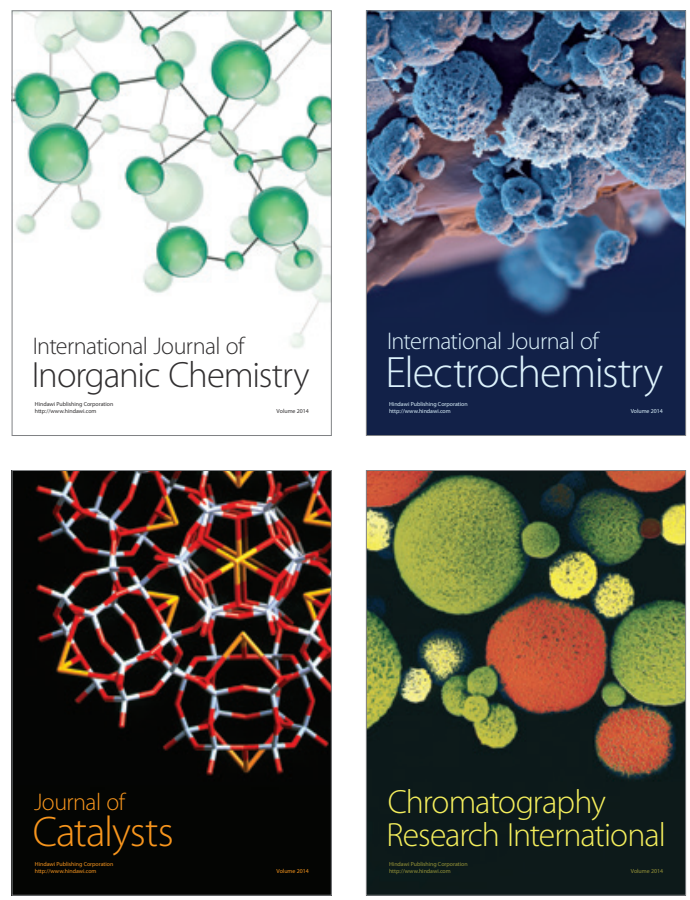
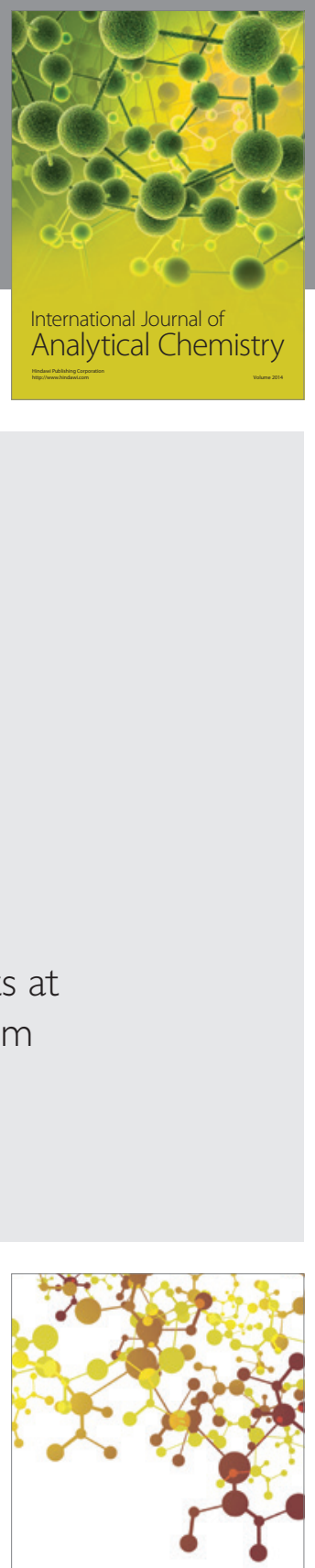

Journal of

Applied Chemistry
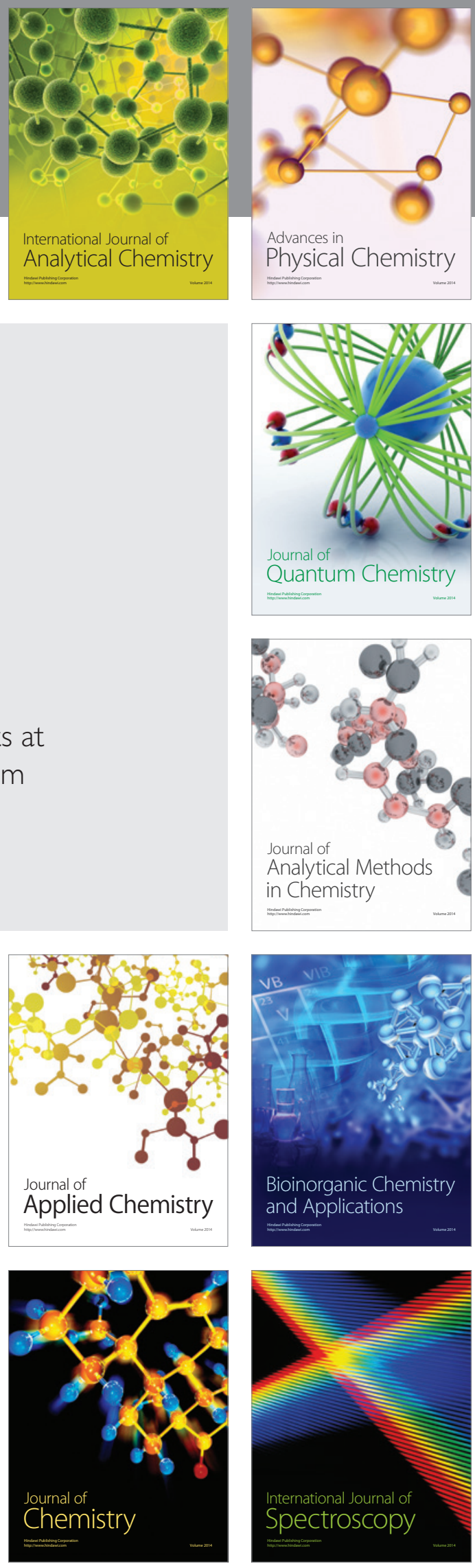